\title{
Editorial
}

\section{Promoting Better Understanding on Sustainable Disaster Risk Management Strategies}

\author{
Christophe Courbage $^{\mathrm{a}}$ and Olivier Mahul ${ }^{\mathrm{b}}$

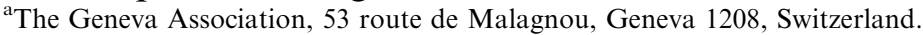 \\ E-mail: christophe_courbage@genevaassociation.org \\ ${ }^{\mathrm{b}}$ Disaster Risk Financing and Insurance Program, FCMNB and GFDRR, The World Bank Office, Bangkok, \\ Thailand. \\ E-mail: omahul@worldbank.org
}

The Geneva Papers (2013) 38, 401-405. doi:10.1057/gpp.2013.20

Over the past 20 years, natural disaster losses have been steadily climbing in both advanced and developing countries. Disaster-related economic losses exceeded US $\$ 400$ bn in 2011 worldwide, the highest ever recorded in history. The Great East Japan Earthquake alone resulted in more than US\$210 bn in damages. Insured losses of over US\$55 bn (out of US\$177 bn total natural disaster losses) made 2012 the third most expensive year on record for the insurance industry. ${ }^{1}$ The upward trend in natural disaster losses is exacerbated by growing urbanisation, environmental degradation and expected increases in the frequency and severity of hydro-meteorological events. Developing countries are particularly vulnerable, as their regulatory systems often cannot keep pace with the rapidly growing asset bases at risk and do not have adequate resources to dedicate to reducing exposure or to effectively respond to an emergency.

There is an urgent need for governments to better understand, manage and reduce the financial and fiscal impacts of natural disasters. Many governments are increasingly recognising the need for comprehensive disaster risk management strategies, including robust disaster risk financing strategies, to achieve sustainable development. In parallel to the increasing attention to disaster risk management, the international community has been working to shift the paradigm of disaster mitigation from response to prevention.

The World Bank has developed an integrated, long-term approach to supporting proactive risk reduction and climate change adaptation in developing countries. In 2006, a consortium of governments together with the World Bank established the Global Facility for Disaster Reduction and Recovery (GFDRR) to better channel global support towards mainstreaming disaster risk management integrated into national development planning. The World Bank/GFDRR helps governments institutionalise sustainable and cost-effective disaster risk financing strategies, within the overall disaster risk management framework, to increase financial resilience to natural disasters through four key pillars: sovereign disaster risk financing, property

\footnotetext{
${ }^{1}$ Swiss Re (2013).
} 
catastrophe risk insurance, agricultural insurance and disaster microinsurance. Governments can implement financial strategies at the sovereign level to increase their financial response capacity in the aftermath of a disaster while protecting their long-term fiscal balance; this approach is known as sovereign disaster risk financing. Governments can also support the development of domestic catastrophe risk insurance markets to transfer financial risks to the insurance sector through property catastrophe risk insurance, agricultural insurance and disaster microinsurance.

As the effort to integrate disaster risk financing and insurance into disaster risk management and climate change adaptation continues to evolve, engaging the private sector yields significant opportunities in the development of innovative disaster risk financing and insurance solutions. Leveraging the private sector through risk transfer schemes, such as catastrophe bonds, insurance and parametric options, provides developing countries with the opportunity to circumvent the issue of nonexistent or underdeveloped domestic private insurance market and instead, directly access the international capital and catastrophe risk transfer markets. The World Bank promotes the role of private insurance and capital markets as innovative disaster risk financing in developing countries. For instance, in 2006, Mexico issued the firstever parametric catastrophe bond by a sovereign, CatMex, to transfer earthquake risk in three zones of the country to the international capital markets. Similar innovations apply to the Caribbean Catastrophe Risk Insurance Facility, the first-ever multicountry regional risk pool, established in 2007 to provide its 16 member countries with access to affordable and effective parametric catastrophe insurance coverage. More recently, in the Pacific region, a regional risk pooling mechanism is being piloted since January 2013 to determine whether a market-based sovereign catastrophe risk transfer instrument can efficiently help to reduce the financial vulnerability of Pacific Island governments to natural disasters. The pilot mechanism secures US $\$ 45 \mathrm{mn}$ of earthquake, tsunami and tropical cyclone catastrophe coverage for five participating Pacific Island governments from four international reinsurance companies and is the first-ever parametric catastrophe risk transfer transaction in the region.

Creating public goods and developing risk market infrastructure fosters the emergence of cost-effective and sustainable insurance solutions that help mitigate disaster-related losses. However, a number of challenges, such as the lack of technical capacity, data, high costs, low awareness and understanding of catastrophe risk exposure, impede the spread of catastrophe insurance market development in developing countries and, in some cases, even in advanced countries. Cooperation between the public and private sectors, facilitated by the international community, can help trigger innovations in product design, risk assessment, operational efficiency and distribution mechanisms to overcome these challenges, and increase catastrophe risk insurance penetration. For example, the Southeast European countries created a specialised regional reinsurer, Europa Reinsurance Facility (Europa Re), in 2009 with the aim of developing private property catastrophe risk insurance markets in the region. Europa Re enables sales of standardised and affordable catastrophe insurance products through its web-based, low-cost insurance market infrastructure. With technical and financial assistance from the World Bank/GFDRR and partnership with participating insurance companies, the Southeast European countries were able to establish a standardised platform to spur the creation of a mass market. 
The contribution of the insurance industry and its significant body of expertise and knowledge on risk management should not be underestimated. Insurers can help in many ways when it comes to managing risks linked to extreme events. They can help in catastrophic modelling and in providing economic incentives to discourage, for instance, construction in high-risk areas. They can contribute to the collection of data on the cost of extreme events. They can promote and increase risk awareness, through publicising their products which encourage individuals to think about their own coverage. They can also be active in developing educational programmes, to the promotion of risk awareness. Insurers can guide and engage customers and suppliers on alternatives in claims handling that are more climate-friendly and weather-proof, leading to more resilient construction methods and adaptation solutions after losses. They can also provide market-based incentives, such as premium reductions on insurance for well-designed homes, or deductibles. Finally, insurers can offer various risk transfer mechanisms.

The Geneva Association has for a long time been interested in the management of natural catastrophe risks and, in particular, in the role and contribution of insurance to the development of efficient natural catastrophe risk management. Many activities have been developed by The Geneva Association to increase this understanding, whether this is through the organisation of conferences and the publication of special materials among which special issues of The Geneva Papers on Risk and Insurance-Issues and Practice. As a consequence of the increasing importance of risks related to natural catastrophes, The Geneva Association in May 2008, following a mandate from its members at the 2008 General Assembly, began its climate risk and insurance research project in response to one of the most multifaceted challenges to the insurance industry since its inception-climate risk. The project builds on the considerable expertise that The Geneva Association has acquired in this area over more than three decades through its activities as part of its ongoing Risk Management Research Programme. The objectives of the climate-linked research have been to identify and analyse, first, issues that are of specific relevance to the insurance industry, such as the likely range of future claims costs, new business opportunities and scenario testing; and second, to study external challenges to be addressed at the political, educational and social levels, such as the role of government, specific provisions concerning issues such as building codes, zoning restrictions, etc., to prevent repeated losses in hazardous regions.

The Word Bank/GFDRR and The Geneva Association have therefore a joint interest in the issues of disaster risk management. These two organisations have developed a partnership to further promote public-private initiatives in disaster risk management and financing, with a special focus on capacity-building. This special issue of The Geneva Papers on Risk and Insurance-Issues and Practice is an illustration of this successful collaboration that aims to foster better knowledge and innovative ideas on the development of effective, affordable and sustainable disaster risk financing strategies.

The following articles contribute to a better understanding of these issues from various perspectives. They range from the effect of natural catastrophes on insurance and economic growth to the appropriate mix of private sector and government responses to catastrophic events, or to the decision process that drives the demand for 
catastrophe bonds. Not only theoretical and empirical issues are tackled, but practical aspects and policy implications are also analysed. These contributions discuss these issues from the perspective of developed and emerging economies: China, the Caribbean, Japan, European countries, the United States and Vietnam.

In the first contribution, Aziz Berdiev and Chun Ping Chang examine the relationship between natural disasters, political risk and insurance market development in a panel of 39 countries over the period 1984-2009 using a dynamic panel system generalised method of moments model. They provide evidence that the incidences of natural disasters and deaths caused by natural disasters lead to greater total insurance, as well as life insurance and non-life insurance consumption. They also find that countries with lower levels of political risk experience higher insurance consumption. Such results show that natural disasters, political risk and their interaction effects are important determinants of insurance market development.

The second contribution by Atsushi Takao, Takuya Yoshizawa, Shuofen Hsu and Takashi Yamasaki investigates how the Great East Japan Earthquake of 11 March 2011 influenced the value of Japanese insurance companies, especially non-life insurance companies. Their findings show, first, that the stock prices of insurance companies decreased right after the earthquake. The spread of this decrease was less for the stock prices of non-life insurance companies than for those of life insurance companies. Second, they show that the more capital buffer a non-life insurance company has, the higher the stock returns. Finally, they show that the Earthquake Insurance System on Dwelling Risks in Japan not only indemnifies seismic losses but also functions as a Japanese stock market stabiliser.

The following paper by Dwight Jaffee and Thomas Russell uses the tools of welfare economics to analyse the appropriate mix of private sector and government responses to catastrophic events. In particular, they examine the appropriate roles of postdisaster government aid, private insurance and mitigation activities. Their analysis applies certain concepts to insurance markets that are now also being developed in the financial literature to examine the efficiency of naked credit default swaps and other instruments which are in essence side bets among agents with heterogeneous beliefs. They conclude that ex post welfare economics provides fundamental insights that have not been previously integrated into the discussions concerning the losses created by catastrophic events, including a potential role for mandatory insurance.

$\mathrm{Xian} \mathrm{Xu}$ and Jiawei Mo investigate the impact of post-disaster transfer payments on economic growth. They first develop a simple two-period equilibrium model, the results of which are tested using Chinese provincial panel data and applying generalised method of moments system estimation. The empirical analysis largely confirms the theoretical predictions. In China, post-disaster transfer payments are found to exacerbate the negative impact of disasters on economic growth. Therefore, the authors suggest that relief should be oriented to create work incentives, in order to avoid its depressing effect on economic growth.

In the next contribution, Ou-Yang Chieh, Erwann Michel-Kerjean and Howard Kunreuther offer an economic analysis of climate adaptations to hurricane risk in the Caribbean island of Saint Lucia. To that aim, they introduce a catastrophic risk model that captures the cumulative impact of climate change on future expected losses from hurricane risk. They use the percentiles of climate change factor to measure expected 
hurricane losses in Saint Lucia. They also undertake benefit-cost analyses on four risk-reduction measures for homes in Saint Lucia and determine when those are cost-effective for different time horizons and discount rates with and without climate change.

Arnaud Reynaud, Cécile Aubert and Manh-Hung Nguyen empirically investigate the determinants of household flood protective strategies and risk perception using data from a household-level survey conducted in spring 2012 in Vietnam. Their empirical analysis shows that some flood protective behaviours of Vietnamese households are driven by the perception of flood risks. Their results also suggest that both perceived probabilities and perceived consequences of floods are related to some cognitive processes included in the Protection Motivation Theory. Lastly, they document the important role played by public flood management policies in shaping individual flood risk perception and protective behaviours.

The main goal of the paper by Alexander Braun, Katja Müller and Hato Schmeiser is to identify major determinants of the cat bond investment decision of insurance and reinsurance companies. For this purpose, they have conducted a comprehensive survey among senior executives in the European insurance industry. Their analysis shows that the expertise and experience with regard to cat bonds, the perceived fit of the instrument with the prevailing asset and liability management strategy, as well as the applicable regulatory regime are significant drivers of an insurer's propensity to invest in cat bonds.

Finally, Calum G. Turvey, Xin Gao, Rong Nie, Linping Wang and Rong Kong examine two challenges faced by China's infant crop insurance industry. The first challenge is operational and arises from the lack of historical crop yield data at the farm household or village level. The second problem relates to a possible disconnect between objective measures of historical yields that are required for actuarial pricing in the supply of insurance and the subjective perceptions of future risk that are required to establish demand. This may call for a substantial subsidy from the Chinese government in order to encourage participation. Their paper examines both issues, including the form of subsidy, through use of the beta-PERT distribution. Their result allows them to argue that the need for subsidising crop insurance premiums is a consequence of the dissonance between subjective and historical risks.

We are proud to deliver this special issue of The Geneva Papers on Risk and Insurance-Issues and Practice on the important topic of disaster risk reduction, as a collaboration between The Word Bank/GFDRR and The Geneva Association. These papers offer important messages for policymakers on how to develop disaster risk financing strategies, including the role of the private insurance sector. We thank each of the authors for providing us with such quality research and we sincerely hope that you will enjoy reading their work.

\section{Reference}

Swiss Re (2013) Natural catastrophes and man-made disasters in 2012: A year of extreme weather events in the US (Sigma No. 2/2013). 